Journal of Engineering Sciences, Assiut University, Vol. 39, No. 4, pp.853- 869, July 2011.

\title{
A MODEL FOR ELECTRICAL TREEING IN EPOXY NANO- COMPOSITE INSULATING MATERIALS
}

\author{
A. Thabet \\ Aswan, Nanotechnology Research Centre NTRC, High Institute of Energy, \\ South Valley University, Aswan, Egypt
}

(Received May 24, 2011 Accepted June 27, 2011)

\begin{abstract}
Electrical treeing is a pre-breakdown mechanism, and is the responsible for the long-term degradation of polymer insulation. This paper has been enhanced both the life-time of tree propagation to breakdown and the tree growth rate of electrical tree propagation by adding various amounts of nanoparticles as Clay, Silica, $\mathrm{ZnO}$, and Al2O3 to various industrial materials CT200 Epoxy Resin, and LY/HY-5052 Epoxy Resin. This research has focused on the development of nanocomposite materials with electrical tree growth resistance superior to the unfilled matrix, and has stressed particularly the effect of filler volume fraction on the breakdown resistance. Finally, this research aims to present a systematic and comparative study about the effect of adding nanoparticles to dielectric insulation, and to understand the role of these nanoparticles, Clay, Silica, ZnO, and Al2O3 particles in the CT200 Epoxy Resin and LY/HY-5052 Epoxy Resin which can made significant improvement in breakdown resistance, life-time of insulation and decreasing the tree growth rate of electrical tree propagation.
\end{abstract}

KEYWORDS: Electrical Treeing, life-time, Tree Propagation, Nanocomposite Materials, dielectric insulation, Nanoparticles

\section{INTRODUCTION}

Over the recent years particulate composites have received much attention particularly with the introduction of nanoparticles. Nanoparticles offer improved mechanical, electrical, and thermal properties of composites at relatively low concentrations. One of the important properties of composites in general is their dielectric properties which have been studied extensively. More recently, research tends to suggest that the dielectric properties of the interphase are also inhomogeneous, varying with respect to the radial distance from the centre of the spherical inclusion [1-3]. A controlled design of the spatial varying property also enables one to control the overall property of composites [2]. Results for the dielectric constant have been published for two-phase composites in which perfect bonding is assumed to exist between the inclusion and the matrix. The results are from Maxwell-Garnett theory [1] with the same result derived later by using the composite spheres assemblage model [4]. This result can also be used for the electrical and thermal conductivity, magnetic permeability and diffusivity, provided that the spherical inclusions and matrix are isotropic. There has been a first principles approach developed to find the effective dielectric response of composites with a dilute suspension of graded spherical particles. Vo and Shi [4] measured the dielectric properties of composites as a function of inclusion concentration using a proposed theoretical model based on effective medium theory [5, 6]. The dielectric 
property of composites and its dependence on the filler concentration is taken into account in their model. Therefore, their model is valid overall volume fractions and showed good agreement with experimental results.

Electrical treeing occurring at voids and impurities is considered the main prebreakdown mechanism of polymeric insulation materials. Its formation is characterized by three main phases: initiation, propagation and breakdown. During the initiation phase, it is assumed that micro-voids are formed in regions of high electric stress without detectable partial discharge activity. In the propagation phase measureable partial discharges cause erosion and development of thin channels across the insulation. This complex process is affected by space charge injection, breaking of polymeric bonds, oxidation and formation gases. During propagation the electric field distribution in the channel is continuously changing, thus the discharge activity will vary within the electric tree. Electric breakdown occurs either when a conductive channel is formed or the breakdown strength of the tree structure is reduced below the applied stress. The result of this is that the shape of electrical tree depends on the magnitude and frequency of the applied electric stress, as well as the material properties. Electrical trees are a common cause of degradation in solid insulation. Electrical trees are erosion channels, which stem from regions with high local electric field (such as voids, cracks, foreign particles etc). Tree growth comprises the formation of gas-filled channels, in which partial discharges occur. Propagation of electrical tree into solid insulation can bridge the electrode gap, causing breakdown to the insulation. The breakdown does not occur when thin channels arrive at the opposite electrode. A certain amount of time is needed for thin channels to turn into thick ones, which are then capable to cause breakdown. The partial discharge activity within the channels is responsible for the channels diameter growth. The characteristics of electrical tree propagation have been found sensitive to electrode geometry, voltage, frequency, temperature and so on. During propagation the electrical tree can adopt variously complex shapes that can be roughly characterized as branch and/or bush-shaped structures. Electrical trees consist of connected channels a few micrometers in diameter, with branches tens of micrometers long. The walls of the channels are not always carbonized and only weakly conducting, thus although a short circuit may occur if the tree bridges the insulation [7-11].

Most researches to date have been done on observing the growing of electrical trees using optical observations, pulse distribution (PD) analysis and PD pulse analysis. However, there is not much work done on investigating the trend of electrical trees prior to breakdown, i.e. analyzing and meaning the important characteristics of partial discharge patterns due to electrical trees right before the insulation breakdown. This would be useful to give an indication of the behavior of the electrical trees before breakdown, i.e. its insulation life is reaching the limit. Studying electrical treeing in polymers, standard test methods referred as needle test method provides statistical estimates of the electrical tree initiation stress. Both metallic and semi-conducting needles can be applied [12-14]. Partial discharges can start at the interfaces and eventually promote inception and growth of electrical trees. The possible reasons for how smaller particles should improve the electrical treeing resistance are discussed and a model for breakdown-resistant of nanocomposite dielectrics is developed. Nanoparticles have great effect of changing the properties of nanocomposite materials 
as electrical tree growth resistance superior to the unfilled matrix, and so, it has stressed particularly the effect of filler volume fraction on the breakdown resistance [15-21].

This paper has been investigated the life-time of tree propagation to breakdown and demonstrated that the tree growth rate of electrical tree propagation by using various types and amounts of nanoparticles. Also, it has been explained the dielectric properties which enhanced by adding nanoparticles of Clay, Silica, Zinc Oxide, and Aluminum Oxide to various types of epoxy resin industrial insulation materials.

\section{ANALYTICAL MODEL}

A system of a propagating electrical tree and the surrounding damage process zone (DPZ) subjected to only alternating current electrical stress as shows in Fig. 1. Is considered during the tree propagation process, the DPZ is visualized to evolve in a self-similar fashion and evolves through the transformation of polymer from some initial morphology to a damaged morphology. In this way the nature of damage is intrinsically related to the microstructure of the polymer. Micro-voids initiate in the $\mathrm{DPZ}$ at the tree tip when the intensity of the local field ultimately builds up to some critical level as shows in Fig. 1.a. The primary tree channel departs from its original straight trajectory to connect to a neighboring cavity being absorbed, and another neighbor cavity is absorbed by the main tree channel to form branching tree channels. Figure 1.b illustrates the microphysical characteristics of tree propagation. Damage in the DPZ ahead of a tree gives rise to micro-voids, which eventually coalesce, as an extension or branch.
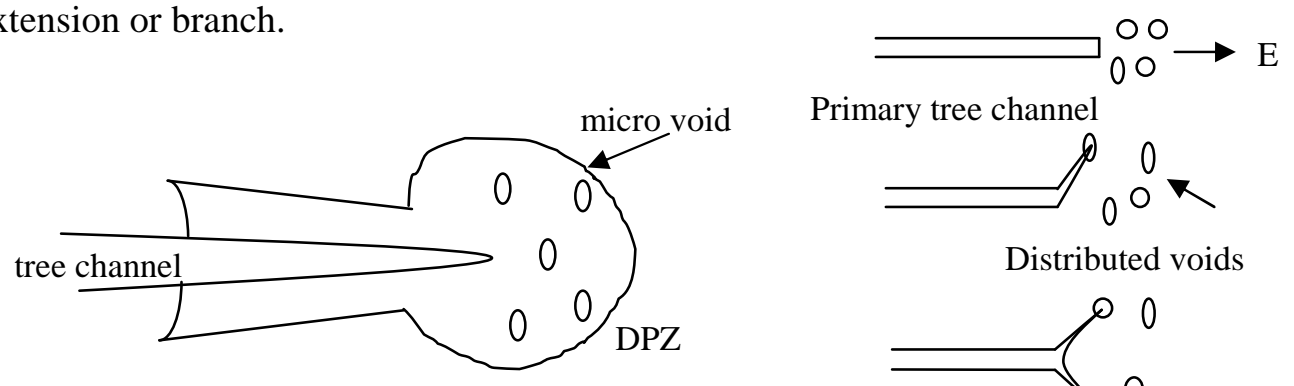

Primary tree channel

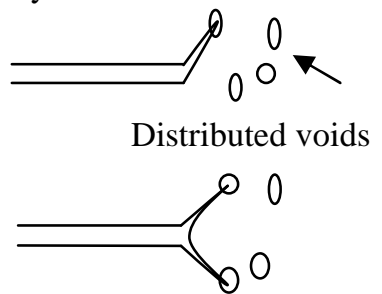

a. Critical damage process zone

b. A propagating tree and its branching process

Figure 1 Damage in the DPZ microstructure of the local field around the tree tip

The characteristic micro-void density and its distribution in the DPZ depend upon material, specimen geometry, and loading conditions. The interval between two consecutive increments of tree propagation depends also on the random distribution of micro voids in the DPZ. The consequence of this approach is therefore that tree propagation is essentially considered here to be a random process and the tree structure can be modeled as a fractal cluster that consists of growing micro-voids. Fractal clusters are characterized by the relationship between L, the linear size of a cluster, and $\mathrm{D}$, the total number of branch elements from which the cluster has been formed. This relationship is a power law with a non-integer exponent $d_{f}[9]$.

$\mathrm{D}=\left(\mathrm{L} / \mathrm{L}_{\mathrm{b}}\right)^{\mathbf{d}_{\mathbf{f}}}$ 
Where, $d_{f}$ is called the fractal dimension, $D$ in present case is the total number of growing micro-voids which have formed the tree structure, $\mathrm{L}$ is the linear length of the tree structure and $\mathrm{L}_{\mathrm{b}}$ is the linear length of a growing micro-void.

A fractal, according to Mandelbrot's explanation, is a shape made of parts similar to the whole in some way. The concept of fractal in the microstructure of materials has been applied with success to various phenomena including fractal behavior of dielectric aging [9], and electrical treeing structures. The physical origin of the formation fractal structures in the case of dielectric ageing and electrical treeing has been explored and reported [10], and it is argued that the fractal behavior determined by the scale-invariance of the degradation evolution dynamic equation. Fractals may not only provide a phenomenological approach to characterizing structures that appear to be self-similar to a certain approximation, but also reveal important information for the theoretical interpretation of the patterning processes, and provide a useful tool in validating models for the evolution of the microstructural elements. The formation and growth of micro-voids in the DPZ ahead of the tree tip, on a submicroscopic level, can be explained and described as follows; the polymer degradation process starts from chain scission and free radical formation due to charge carrier injection and thus causing a few weak regions to create. Accumulation of breakages originating from one site during a period of AC voltage application can be considered as void. This is the stage of submicroscopic void formation. The size of these submicroscopic voids is of the order of 10-1000 $\mathrm{A}^{\circ}$ and is dependent on the specific polymeric structure. Then, in these submicroscopic voids, the local electrical field intensity increases, therefore causing more and successive bond breakdown, which is the stage of submicroscopic void growth. Eventually, a number of these submicroscopic voids coalesce into macroscopic tree branches.

In order to model the process of micro-void formation and growth in the DPZ, we can think of a micro-void of linear size $\mathrm{L}_{\mathrm{o}}$ in the direction of electric field confined by an effective potential well depth $U_{o}$, as described in detail in [9]. The formation and growth of such a micro-void requires the breaking of chemical bonds which takes place via a thermally activated process, with activation energy $U_{0}$. In a local electric field energy is stored that reduces the initial energy barrier $U_{\sigma}$ by the amount $\alpha C_{0} \pi \varepsilon E^{2}$ here $\mathrm{E}$ is the local electric field strength, $\varepsilon$ is the dielectric permittivity, $\pi$ is a numeric constant, $G^{a} \equiv \pi \varepsilon E^{2}$ represents the amount of electrostatic energy released when the micro-void grows by a unit length and is called the micro-void extension force per unit length; the parameter $\alpha$ is a property of the material, which represents the activation area in the direction of electric field, and $\alpha \mathrm{C}_{o}$ means the volume activated by the local electric field. A general dependence of the micro-void growth frequency $\mathrm{K}$ on local electric field strength $\mathrm{E}$ and temperature $\mathrm{T}$ has been previously determined by computing the reaction rate constant for bond breakdown as follow [9].

$$
\mathbf{K}=\left(\frac{\mathrm{hT}}{\mathrm{h}}\right) \exp \left(\frac{\mathrm{aC}_{0} \Pi \mathrm{E}^{2}-\mathrm{U}_{0}}{\mathrm{kT}}\right)
$$

Where, $\mathrm{k}=1.38 \times 10^{-23} \mathrm{JK}^{-1}$ and $\mathrm{h}=6.626 \times 10^{-34} \mathrm{~J} . \mathrm{s}$ are the Boltzmann and Planck constants, respectively.

The growth kinetic of an electrical tree structure can now be described quantitatively. On the average, a unit increment of the electrical treeing damage occurs in a time interval, which is equal to the average time between two consecutive 
increments of tree extension. Assuming that $\mathrm{N}_{\mathrm{b}}$ is the number of growing micro-voids necessary to allow a branch of length $\mathrm{L}_{\mathrm{b}}$ to form, and all growing micro-voids in the DPZ have the same growth frequency $\mathrm{K}$ determined by Eq. 2 . We can calculate the rate of formation of new branches from the micro-void formation and growth as $K / \mathrm{N}_{\mathrm{b}}$. In order to formulate an expression for the rate of tree structure growth from the microvoid formation and growth in the DPZ, it is further assumed that a tree structure will propagate provided at least one new branch to be formed via coalescence of a number of growing micro-voids. The rate of overall treeing damage $(\mathrm{dD} / \mathrm{dt})$ can thus be generally determined as:

$\frac{\mathrm{dD}}{\mathrm{dt}}=\frac{\mathrm{K}}{\mathrm{N}_{\mathrm{b}}}=\left(\frac{\mathrm{kT}}{\mathrm{h}}\right) \cdot \exp \left(\frac{\mathrm{aC}_{\mathrm{g}} \pi \mathrm{EE} \mathrm{E}^{2}-\mathrm{U}_{o}}{\mathrm{kT}}\right)$

For the simplest case, i.e., $\mathrm{N}_{\mathrm{b}}=1$ in Equ. 3, which means that a tree propagates after one growing micro-void in the DPZ is absorbed for the formation of a new branch. Obviously, the electrical treeing damage evolution law depends not only on the specific physical mechanism of the formation and growth of micro-voids; also, by substituting Eq. 1 into Eq. 3, an electrical tree growth rate equation will be as follows:

$\frac{\mathrm{dL}}{\mathrm{dt}}=\frac{\mathrm{dL}}{\mathrm{dD}} \cdot \frac{\mathrm{dD}}{\mathrm{dt}}=\frac{\mathrm{kT} \mathrm{L}_{\mathrm{h}}^{\mathrm{d}_{\mathrm{f}}}}{\mathrm{h} \mathrm{Nb} \mathrm{d}_{\mathrm{f}}} \mathrm{L}^{\left(1-\mathrm{d}_{\mathrm{f}}\right)} \exp \left(\frac{\mathrm{aC}_{a} \pi \mathrm{E}^{2}-\mathrm{v}_{\mathrm{a}}}{\mathrm{kT}}\right)$

By integrating Eq. 4, to establish the electrical tree growth law as:

$L=L_{b}\left\{\frac{k T}{h N_{b}} \exp \left(\frac{a C_{g} \pi \varepsilon E^{2}-U_{a}}{k T}\right)\right\}^{1 / d_{f}} t^{1 / d_{f}}$

The time of tree growth to failure $t_{g}$, assuming initial tree length $L_{0}=0$ to a critical tree length $\mathrm{L}_{\mathrm{c}}$, i.e.

$t_{\mathrm{g}}=\left(\frac{L_{C}}{L_{b}}\right)^{d_{f}} \frac{h N_{b}}{k T} \exp \left(\frac{v_{a}-a C_{a} \pi \varepsilon E^{2}}{k T}\right)$

The local electric field strength in the pin-plane sample can be approximately calculated by:

$E=\frac{2 V}{r \ln \left(1+\frac{4 R / r}{r}\right)}$

Where: $\mathrm{V}$ is the applied voltage across the sample, $\mathrm{r}$ is the pin-tip-plane separation, $\mathrm{T}=300 \mathrm{~K}$ and approximately $\mathrm{L}_{\mathrm{c}}=2 \times 10^{-3} \mathrm{~m}$, i.e. the pin-tip-plane separation being taken as the critical tree length for breakdown $\mathrm{r}=10^{-6} \mathrm{~m}$, $\mathrm{R}=2 \times 10^{-3} \mathrm{~m}$. Noting that,

$\mathbf{d}_{\mathrm{fc}}=\mathbf{d}_{\mathbf{f}}+\mathbf{f}$

Where, $f$ is volume fraction of the nanofiller, $d_{f c}$ is the fractal dimension of the composite, and $\mathrm{d}_{\mathrm{f}}$ is the fractal dimension of polymer.

\section{SELECTED INDUSTRIAL MATERIALS}

\subsection{Nanoparticles}

- Clay mineral used in the polymer industry is kaolinite. Kaolinite is the main constituent of filler clays, significant quantities of other minerals can often be present. The particle shape is the most important characteristic of kaolinite for polymer applications. The platy nature means that clay fillers have a greater effect on properties such as viscosity, stiffness and strength, using clay as nano 
filler gives high levels of flame retardancy to the produced composite, and it's selected in this study. Cost less of Clay catalyst to be the best filler among nano-fillers industrial materials.

- Silica: The chemical compound silicon dioxide, also known as silica nanosilica with typical particle size of $10 \sim 50 \mathrm{~nm}$ is widely used as fillers to improve the mechanical and thermal properties of polymers.

- Zinc Oxide $(\mathrm{ZnO})$ is a popular cross-linker for rubber and for various resins, it is also used as an UV stabilizer, and it has a relatively high refractive index which makes it an efficient white pigment.

- Aluminum oxide $\left(\mathrm{Al}_{2} \mathrm{O}_{3}\right)$ is used for its hardness and strength. It is widely used as a coarse or fine abrasive, including as a much less expensive substitute for industrial diamond.

\subsection{Industrial Polymers}

- CT200 Epoxy Resin, Epoxy based insulation is widely used in electrical engineering e.g. for transformers, rotating machines, bushings or cable terminations. It has excellent dielectric and mechanical properties, chemical stability and can be shaped into any form necessary.

- Araldite LY5052 and an amine Hardener HY5052: it consists of an epoxy resin Araldite LY5052 and an amine Hardener. The LY/HY 5052 epoxy resin is one of the most important hard cast-types of resins employed in high voltage insulation technology. Input Data of industrial materials which are used in this research has depicted in Table (1). Also, it is cleared that, table 2 which shows the relative permittivity's of the neat CT200 epoxy resin and its nanocomposite materials of neat CT200 epoxy resin with 5\% volume fraction.

Table 1. Input Data of Suggested Industrial Materials

\begin{tabular}{|c|c|}
\hline Industrial Materials & Input Data \\
\hline CT200 Epoxy Resin & $\begin{array}{l}\mathrm{c}_{\mathrm{o}}=0.56 \times 10^{-28} \mathrm{~m}^{2}, \mathrm{U}_{\mathrm{s}}=1.382 \times 10^{-19} \mathrm{~J} \\
\mathrm{~L}_{\mathrm{b}}=10^{-5} \mathrm{~m}, \varepsilon=5 \times 8.85 \times 10^{-12} \mathrm{fm}^{-1}, \mathrm{~d}_{\mathrm{f}}=1.35\end{array}$ \\
\hline $\begin{array}{c}\text { LY/HY } 5052 \text { Epoxy } \\
\text { Resin }\end{array}$ & $\begin{array}{l}\alpha c_{0}=0.71 \times 10^{-28} \mathrm{~m}^{2}, \mathrm{U}_{0}=1.387 \times 10^{-19} \mathrm{~J} \\
\mathrm{~L}_{\mathrm{b}}=10^{-5} \mathrm{~m} \\
\varepsilon=5 \times 8.85 \times 10^{-12} \mathrm{Fm}^{-1}, \mathrm{~d}_{\mathrm{f}}=1.45\end{array}$ \\
\hline
\end{tabular}

Table 2. Dielectric Constants of CT200/ LY/HY5052 Epoxy Resin and Their Nano-Composites

\begin{tabular}{c|c}
\hline Industrial Materials & Dielectric Constant \\
\hline PURE CT200/ LY/HY5052 Epoxy Resin & 5 \\
$5 \mathrm{wt} \%+$ Clay / Epoxy Resin & 4.24 \\
$5 \mathrm{wt} \%+$ Silica / Epoxy Resin & 4.4 \\
$5 \mathrm{wt} \%+\mathrm{ZnO} /$ Epoxy Resin & 4.22 \\
$5 \mathrm{wt} \%+\mathrm{Al}_{2} \mathrm{O}_{3}$ / Epoxy Resin & 5.29 \\
\hline
\end{tabular}




\section{RESULTS AND DISCUSSION}

\subsection{Effect of Voltage on Life-Time of Nano-Composite Insulation Materials}

\subsubsection{CT200 Epoxy Resin}

Figure 2.a shows that the fractal dimension is 1.1 up to 1.5 for the mean value of 10 different results for various applied voltage, and it is obvious that.

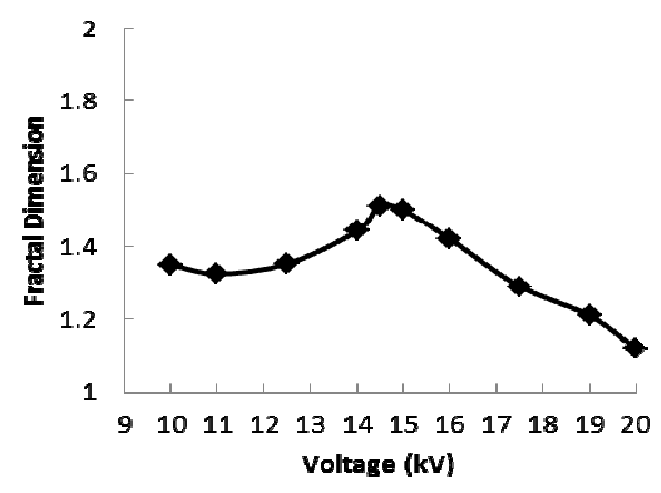

(a) Fractal dimension of electrical tree growth

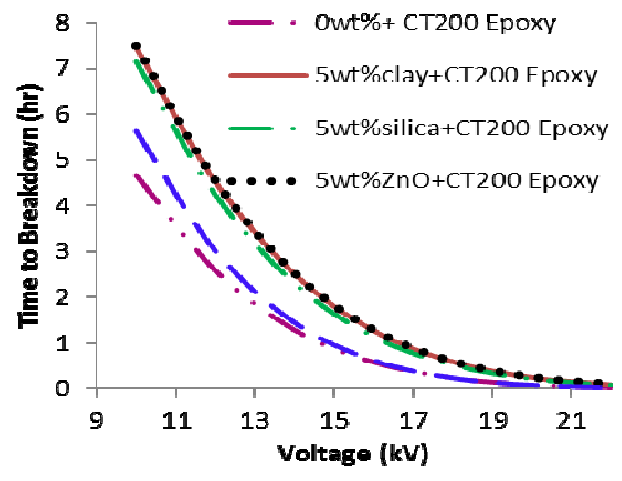

(b) CT200 epoxy resin nanocomposites

Fig. (2) Effect of voltage on the life-time of CT200 Epoxy Resin materials

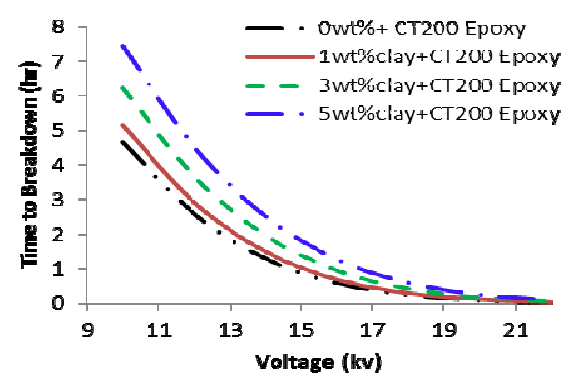

(a) Clay

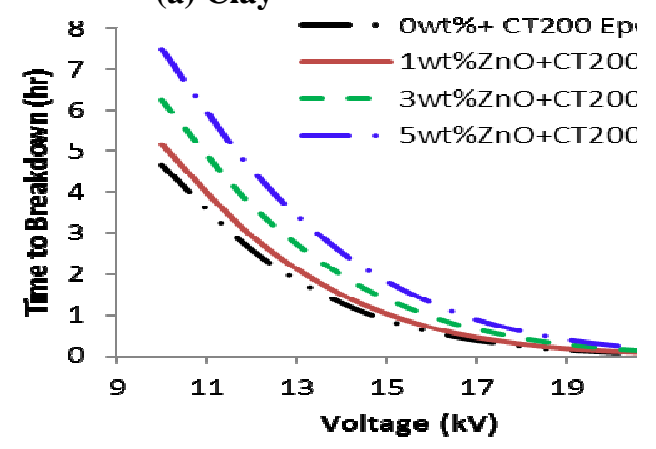

(c) $\mathrm{ZnO}$

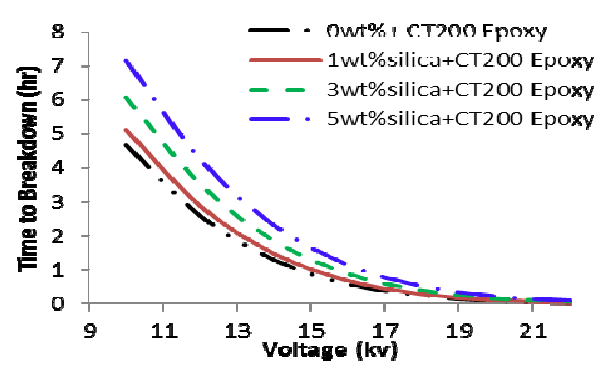

(b) Silica

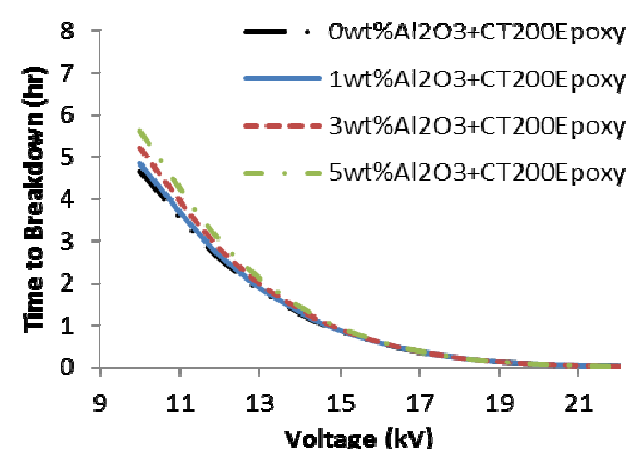

(d) $\mathrm{Al} 2 \mathrm{O} 3$

Fig. 3 Effect of voltage on the life-time CT200 Epoxy Resin nanocomposites 
From Fig. 2.b it's obvious that the life-time characteristics of CT200 epoxy resin before and after adding $5 \mathrm{wt} \%$ of nanoparticles (clay, silica, $\mathrm{ZnO}$ and $\mathrm{Al}_{2} \mathrm{O}_{3}$ ) which leads to increase the electrical treeing time to breakdown compared with the neat CT200 epoxy resin insulation materials. The improvement in electrical treeing time to breakdown is backing to the effects of nanofillers (Clay, Silica, $\mathrm{Al}_{2} \mathrm{O}_{3}$ and $\mathrm{ZnO}$ ) due to changing the dielectric properties of the neat CT200 Epoxy Resin. Figures 3 (a, b, c, and d) show the life-time decreases exponentially by increasing the applied voltage at various amounts of nanoparticles $(1,3$ and $5 \mathrm{wt} \%$ of Clay, Silica, $\mathrm{ZnO}$ and $\mathrm{Al}_{2} \mathrm{O}_{3}$ ) to CT200 epoxy resin. It is noticed that, the improvement has increased with increasing the percentages of nanoparticles (Clay, Silica, $\mathrm{ZnO}$ and $\mathrm{Al}_{2} \mathrm{O}_{3}$ ) but the improvement in electrical treeing time to breakdown is being slightly whenever adding $\mathrm{Al}_{2} \mathrm{O}_{3}$ nanoparticles to the CT200 epoxy resin, this is due to high dielectric constant value of the nanoparticles.

\subsubsection{LY/HY5052 Epoxy Resin}

Figure 4.a shows that the fractal dimension is changed from 1.3 up to 1.6 for 10 different values of applied voltages. Figure 4.b shows the life-time of LY/HY5052 epoxy resin nanocomposites which having $5 \mathrm{wt} \%$ nanoparticles of (Clay, Silica, $\mathrm{Al}_{2} \mathrm{O}_{3}$ and $\mathrm{ZnO}$ ). It is noticed that, the electrical treeing time to breakdown increases with increasing applied voltage compared with the neat LY/HY5052 epoxy resin. High improvement has been occurred by adding percentages amounts of certain nanofillers (Clay, Silica, and $\mathrm{ZnO}$ ) to the LY/HY5052 epoxy resin but, low improvement has been occurred whenever adding the same percentages of of $\mathrm{Al}_{2} \mathrm{O}_{3}$ nanofillers to neat LY/HY5052 epoxy resin, this is due to high dielectric constant value of the nanoparticles. Noting that, types and percentage of nanofillers in epoxy eesin is the main reasons for decreasing or increasing the improvement life-time of the nanocomposite.

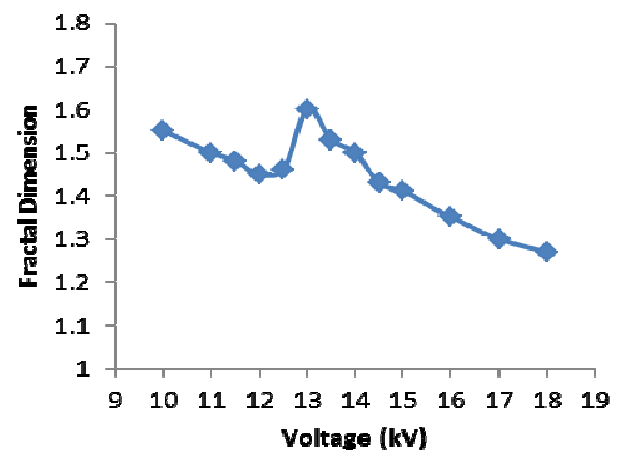

(a) Fractal dimension of electrical tree growth

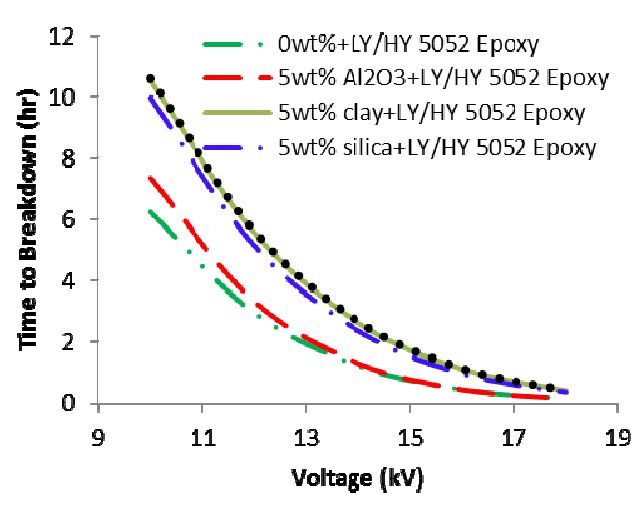

(b) LY/HY 5052 epoxy resin nanocomposites

Fig. (4). Effect of voltage on the life-time of insulation, with LY/HY 5052 Epoxy Resin 
Figures 5 ( $\mathrm{a}, \mathrm{b}, \mathrm{c}$, and d) show the life-time to breakdown for various nanocomposites of LY/HY5052 epoxy resin that have been various percentages of nanofilles (Clay, Silica, $\mathrm{Al}_{2} \mathrm{O}_{3}$ and $\mathrm{ZnO}$ ). It is cleared that the life-time to breakdown decreases exponentially with increasing voltage at percentages 1,3 and $5 \mathrm{wt} \%$ respectively for all added nanofillers (Clay, Silica, $\mathrm{Al}_{2} \mathrm{O}_{3}$ and $\mathrm{ZnO}$ ) in the LY/HY 5052 epoxy resin. Life-time to breakdown (hours) is improved at high values by increasing the percentages of clay, silica, and zinc oxide nanofillers respectively, while low changes in life-time to breakdown (hours) has been occurred by adding aluminum oxide nanoparticles to the LY/HY5052 epoxy resin.

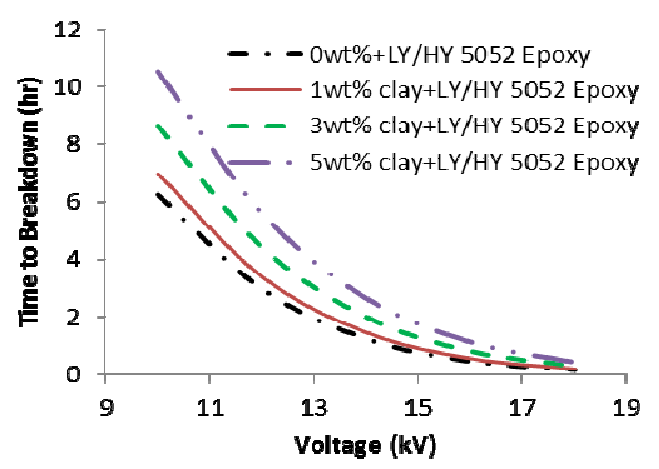

(a) Clay

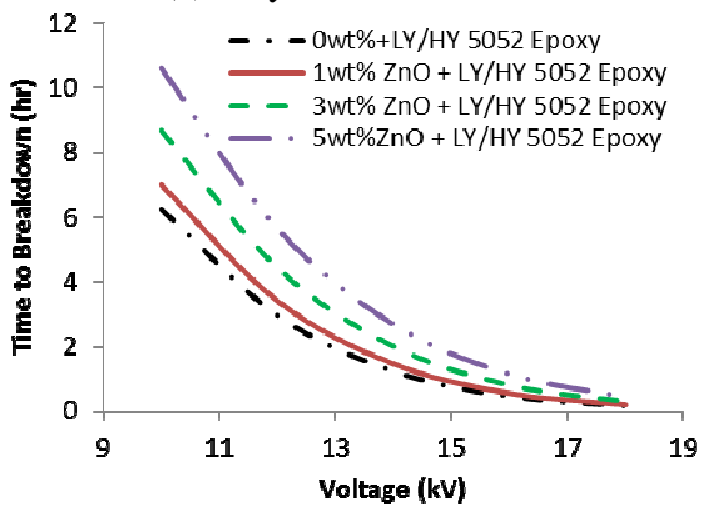

(c) $\mathrm{ZnO}$

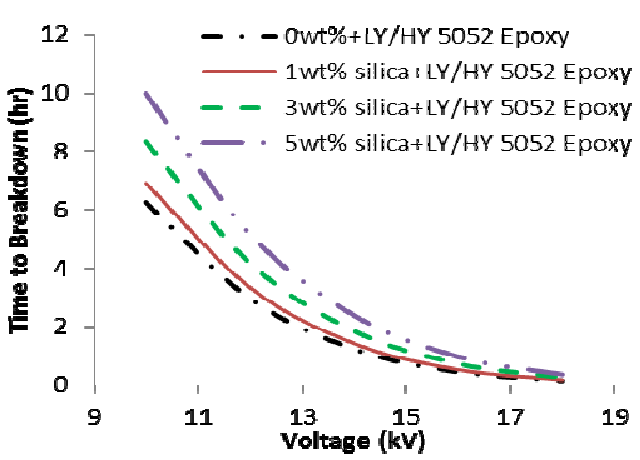

(b) Silica

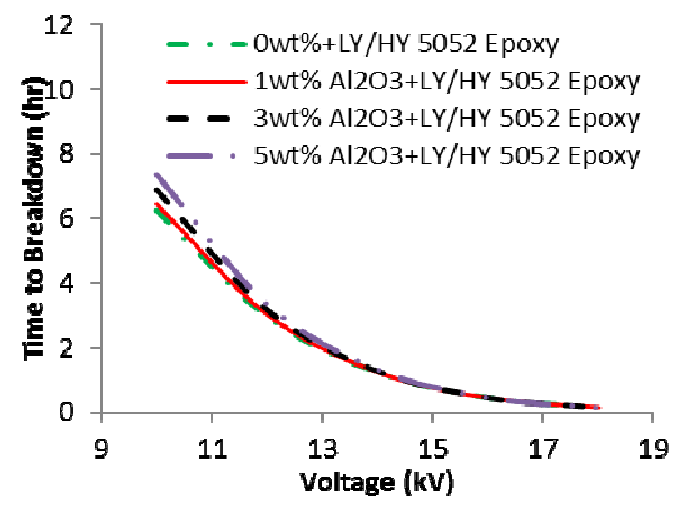

(d) $\mathrm{Al}_{2} \mathrm{O}_{3}$

Fig. (5) Effect of voltage on the life-time of LY/HY 5052 Epoxy Resin nanocomposites

\subsection{Effect of Time on the Tree Radial Extent in Nano-composite Insulation Materials}

\subsubsection{CT200 Epoxy Resin}

Figure. 6 illustrates that tree radial extent with time at $15 \mathrm{kV}$ by using various nanocomposite materials which made by adding $5 \mathrm{wt} \%$ of nanofillers (Clay, Silica, $\mathrm{ZnO}$, and $\mathrm{Al}_{2} \mathrm{O}_{3}$ ) to the $\mathrm{CT} 200$ epoxy resin. Tree radial extent has been increased with time at $15 \mathrm{kV}$ by using various nanocomposite materials of CT200 epoxy resin with 
adding $5 \mathrm{wt} \%$ of nanofillers (Clay, Silica, $\mathrm{ZnO}$, and $\mathrm{Al}_{2} \mathrm{O}_{3}$ ). It has been noticed that the tree length is decreasing by addition of $5 \mathrm{wt} \%$ nanoparticles (Clay, Silica, $\mathrm{ZnO}$, and $\mathrm{Al}_{2} \mathrm{O}_{3}$ ) in $\mathrm{CT} 200$ epoxy resin. $\mathrm{Al}_{2} \mathrm{O}_{3}$ nanoparticles have the lower effect on the tree length than the other nanoparticles (Clay, Silica, and $\mathrm{ZnO}$ ).

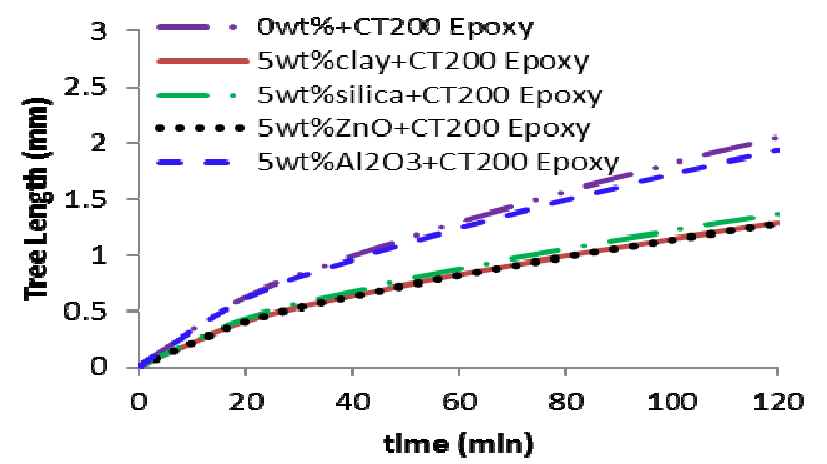

Fig. (6) Effect of time on the tree length, with the neat CT200 Epoxy Resin nanocomposites

Figures 7 (a, b, c, and d) illustrate that the tree length with time at $15 \mathrm{kV}$ for CT200 epoxy resin added with 1, 3, and 5wt\% nanoparticles (Clay, Silica, $\mathrm{ZnO}$ and $\mathrm{Al}_{2} \mathrm{O}_{3}$ ) respectively. It is noticed that the tree length with time decreases with increasing the percentages of clay, silica, and zinc oxide clearly, but the characteristics of tree length with time decreases slightly for of CT200 epoxy resin with various percentages of $\mathrm{Al}_{2} \mathrm{O}_{3}$.
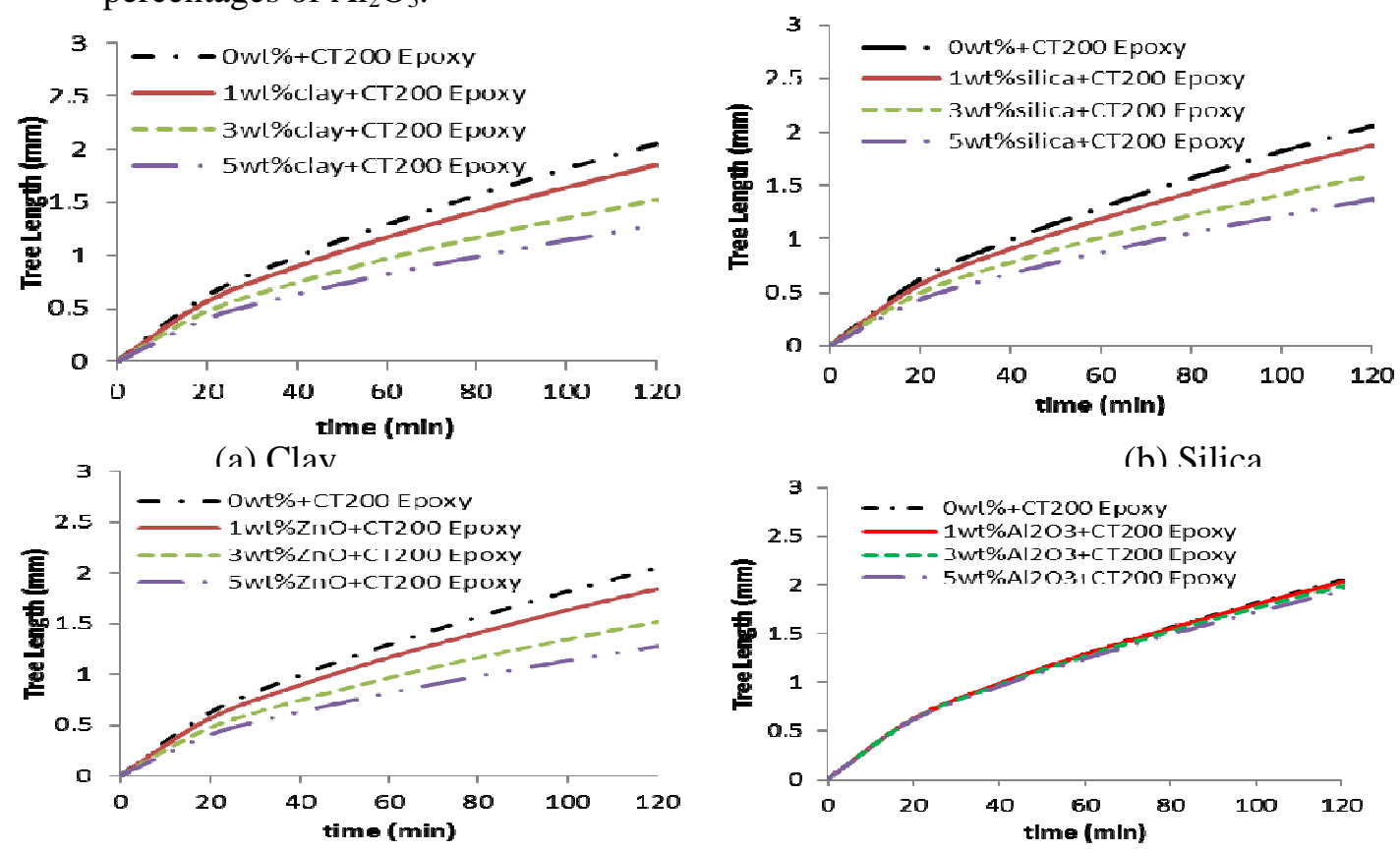

(c) $7 \mathrm{nO}$

(d) $\mathrm{Al}_{2} \mathrm{O}_{2}$

Fig. (7). Effect of time on the tree length in the CT200 Epoxy Resin nanocomposites 


\subsubsection{LY/HY5052 Epoxy Resin}

Figure 8 illustrates that tree radial extent with time at $15 \mathrm{kV}$ by using various nanocomposite materials which made by adding $5 \mathrm{wt} \%$ of nanofillers (Clay, Silica, $\mathrm{ZnO}$, and $\mathrm{Al}_{2} \mathrm{O}_{3}$ ) to the $\mathrm{LY} / \mathrm{HY} 5052$ epoxy resin.

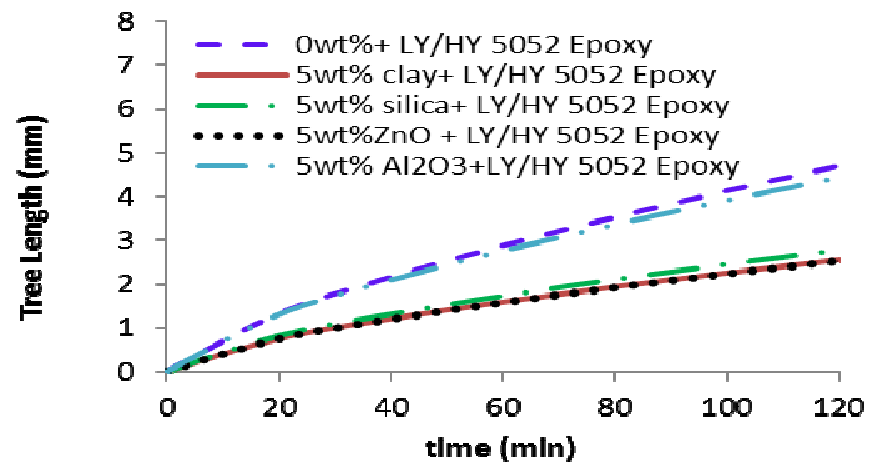

Fig. (8). Effect of time on the tree length in the LY/HY 5052 Epoxy Resin nanocpmposites

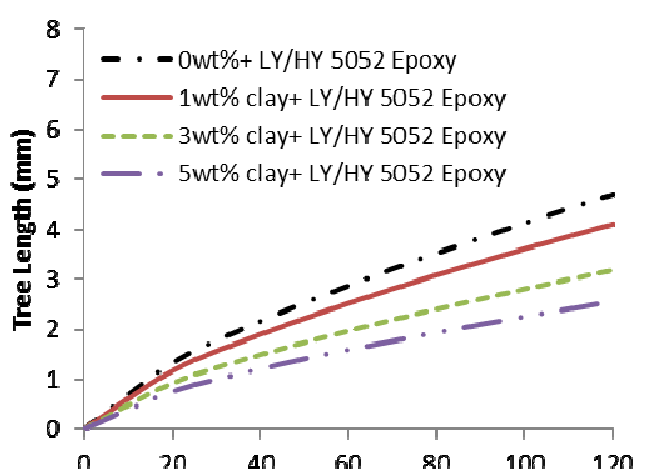

(a) Clay

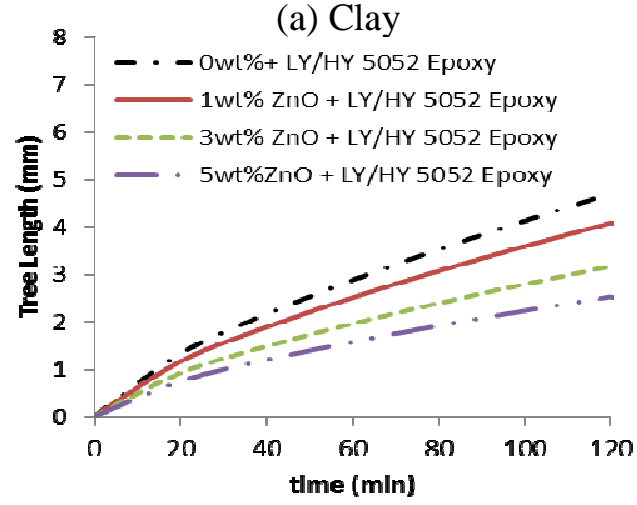

(c) $\mathrm{ZnO}$

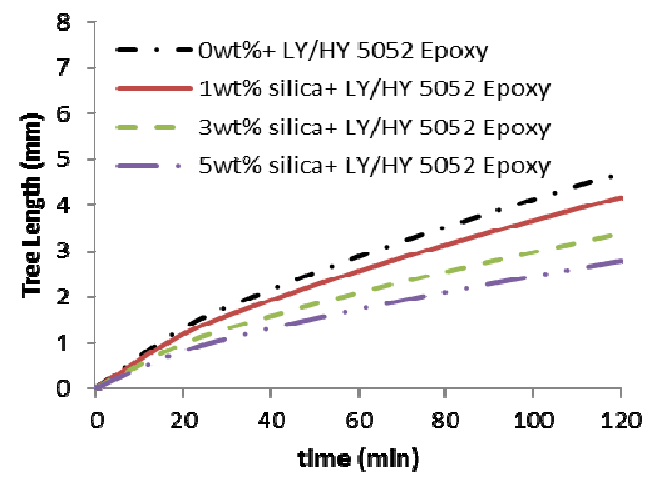

(b) Silica

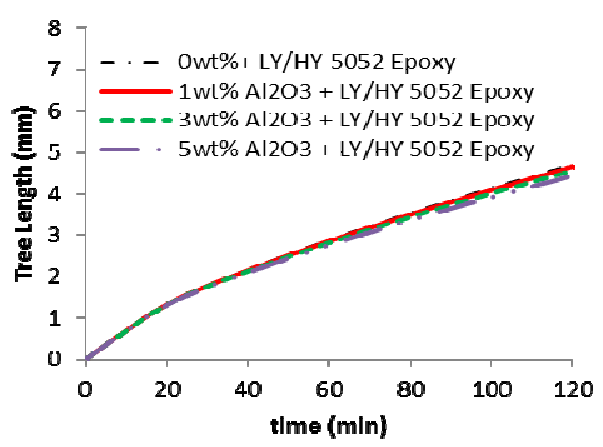

(d) $\mathrm{Al} 2 \mathrm{O} 3$

Fig. (9). Effect of time on the tree length in the LY/HY 5052 Epoxy Resin nanocomposites

Tree radial extent has been increased with time at $15 \mathrm{kV}$ by using various nanocomposite materials of LY/HY5052 epoxy resin with adding $5 \mathrm{wt} \%$ of nanofillers 
(Clay, Silica, $\mathrm{ZnO}$, and $\mathrm{Al}_{2} \mathrm{O}_{3}$ ), but it has been noticed that the tree length is decreasing by addition of $5 \mathrm{wt} \%$ nanoparticles (Clay, Silica, $\mathrm{ZnO}$, and $\mathrm{Al}_{2} \mathrm{O}_{3}$ ) in LY/HY5052 epoxy resin. $\mathrm{Al}_{2} \mathrm{O}_{3}$ nanoparticles have the lower effect on the tree length than the other nanoparticles (Clay, Silica, and $\mathrm{ZnO}$ ). Figures 9 (a, b, c, and d) illustrate that the tree length with time at $15 \mathrm{kV}$ for LY/HY5052 epoxy resin added with 1,3 , and $5 \mathrm{wt} \%$ nanoparticles (Clay, Silica, $\mathrm{ZnO}$ and $\mathrm{Al}_{2} \mathrm{O}_{3}$ ) respectively. It is noticed that the tree length with time decreases with increasing the percentages of clay, silica, and zinc oxide clearly, but the characteristics of tree length with time decreases slightly for of LY/HY5052 epoxy resin with various percentages of $\mathrm{Al}_{2} \mathrm{O}_{3}$.

\subsection{Effect of Fractal Dimension on Life-Time of Nano-Composite Insulation Materials \\ 4.3.1 CT200 Epoxy Resin}

Figure $10(a, b, c, d)$ presents the effect of fractal dimensions of electrical tree growth which are dependent on the applied-voltage on various nanocomposites (CT200 epoxy resin with 1,3 , and $5 \mathrm{wt} \%$ of Clay, Silica, $\mathrm{ZnO}$ and $\mathrm{Al}_{2} \mathrm{O}_{3}$ respectively). It is noticed that, there is high improvement in the electrical treeing time to breakdown compared with the neat CT200 epoxy resin by using Clay, Silica, and $\mathrm{ZnO}$ nanofillers respectively, but, there is a slight improvement by using $\mathrm{Al}_{2} \mathrm{O}_{3}$ nanoparticles. Life-time value at $14.5 \mathrm{kV}$ is a focal value which depends on the behavior of the fractal dimension in the insulation material and its effects on electrical tree growth. Life-time of CT200 epoxy resin is equal to zero at $20 \mathrm{kV}$.

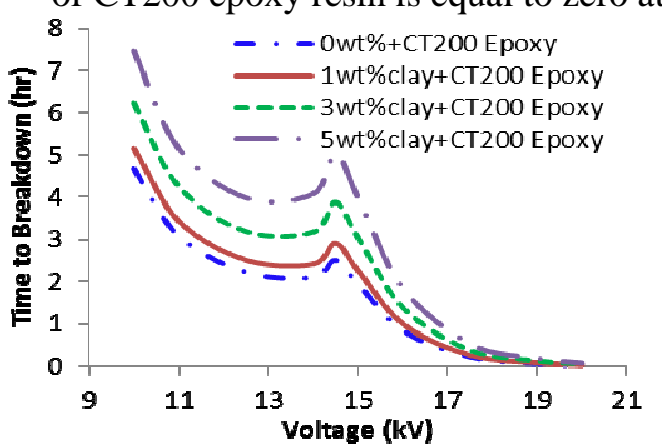

(a) Clay

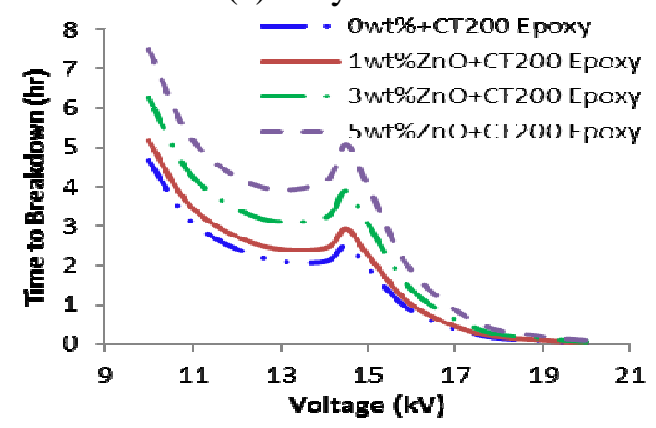

(c) $\mathrm{ZnO}$

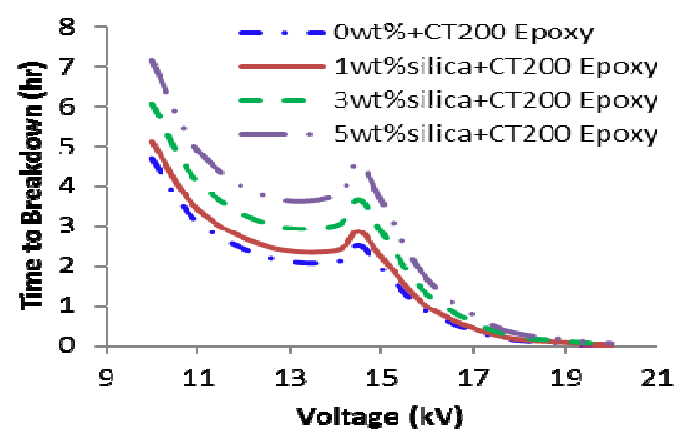

(b) Silica

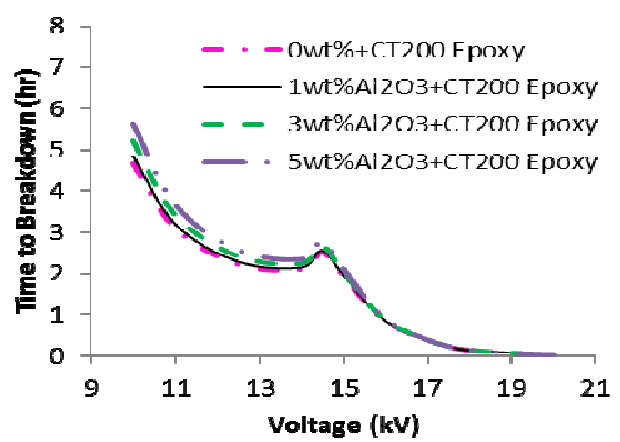

(d) $\mathrm{Al} 2 \mathrm{O} 3$

Fig. (10) Effect of fractal dimension as function of voltage on the life-time of insulation with CT200 Epoxy Resin 


\subsubsection{LY/HY5052 Epoxy Resin}

Figure $10(a, b, c, d)$ presents the effect of fractal dimensions of electrical tree growth which are dependent on the applied-voltage on various nanocomposites (LY/HY5052 epoxy resin with 1,3 , and $5 \mathrm{wt} \%$ of Clay, Silica, $\mathrm{ZnO}$ and $\mathrm{Al}_{2} \mathrm{O}_{3}$ respectively). It is noticed that, there is high improvement in the electrical treeing time to breakdown compared with the neat LY/HY5052 epoxy resin by using Clay, Silica, and ZnO nanofillers, but, there is a slight improvement by using $\mathrm{Al}_{2} \mathrm{O}_{3}$ nanoparticles respectively. Life-time value at $13.5 \mathrm{kV}$ is a focal value which depends on the behavior of the fractal dimension in the insulation material and its effects on electrical tree growth.

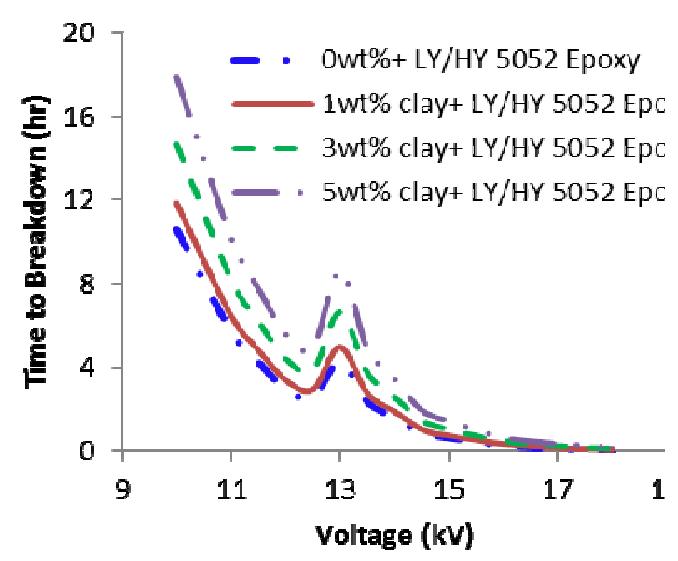

(a) Clay

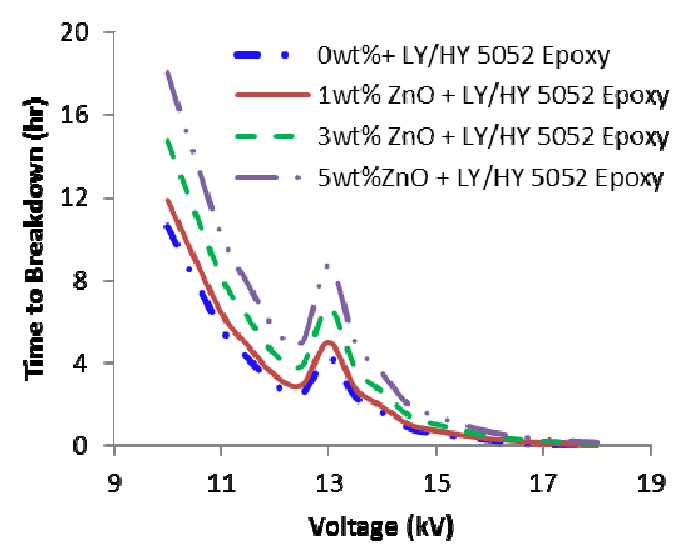

(c) $\mathrm{ZnO}$

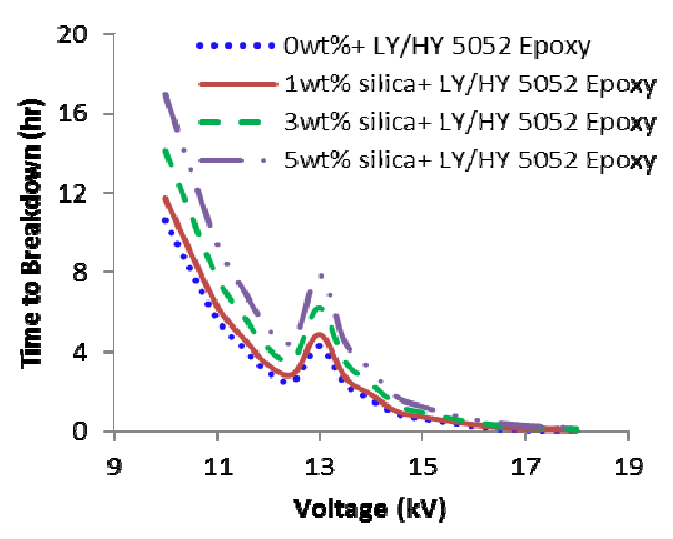

(b) Silica

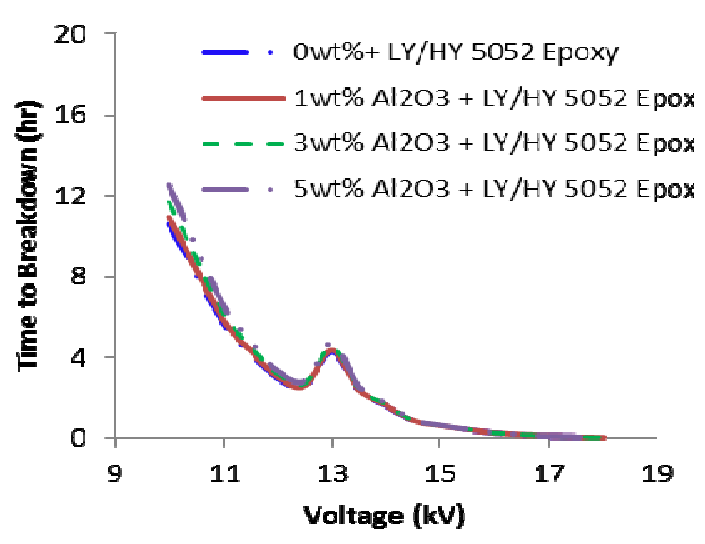

(d) $\mathrm{Al}_{2} \mathrm{O}_{3}$

Fig. (11) Effect of fractal dimension as function of voltage on the life-time of insulation with LY/HY 5052 Epoxy Resin

Noting that, Figures (3, and 5) show the life-time characteristics of CT200 epoxy resin before and after adding $5 \mathrm{wt} \%$ of nanoparticles (clay, silica, $\mathrm{ZnO}$ and $\left.\mathrm{Al}_{2} \mathrm{O}_{3}\right)$ using mean fractal dimension of nanocomposite, but here, Figures $(10,11)$ presents the effect of fractal dimensions of electrical tree growth which are dependent 
on the applied-voltage on various nanocomposites (CT200 epoxy resin with 1, 3, and $5 \mathrm{wt} \%$ of Clay, Silica, $\mathrm{ZnO}$ and $\mathrm{Al}_{2} \mathrm{O}_{3}$ respectively).

\subsection{Effect of Filler Volume Fraction on Life-Time of Nano- Composite Insulation Materials}

Figures 12 ( $a$, and $b$ ) show the characteristics of life-time of insulation with increasing percentages of nanofillers "volume fraction". It has been cleared that life-time of insulation increases with increasing percentage of clay, silica, zinc oxide and aluminum oxide nanoparticles in CT 200 epoxy resin, LY/HY5052 epoxy resin. With respect to the effect of Figures 12 (a, and b), it is cleared that Clay, $\mathrm{ZnO}$, and Silica are the best nanofillers for enhancing the electrical tree time to breakdown.

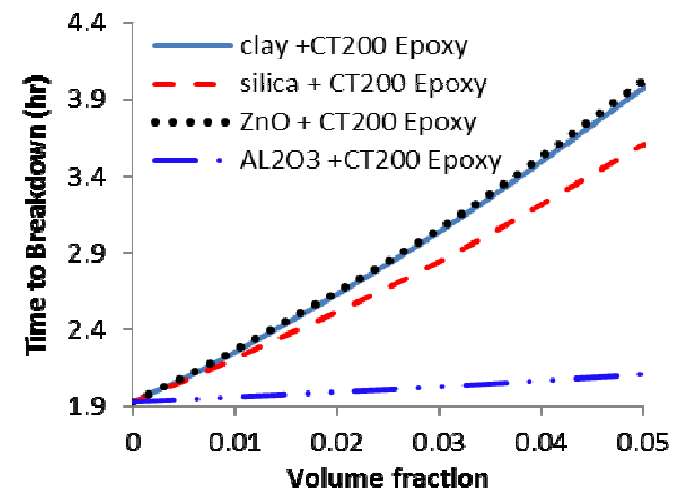

(a) CT200 epoxy resin

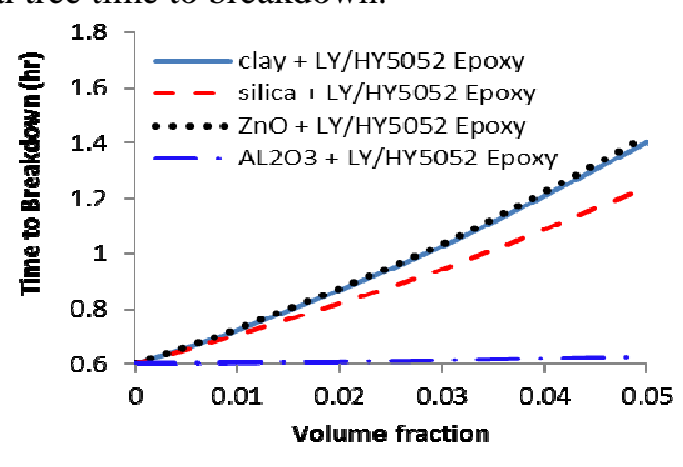

(b) LY/HY5052 epoxy resin

Fig. (12) Effect of volume fraction on the life-time of Epoxy Resin types

\subsection{Effect of Filler Volume Fraction on Fractal Dimension of Insulation Materials}

Effect of filler volume fraction on fractal dimension with the content of the modified particles in the $0-5 \mathrm{wt} \%$ range as shows Fig. 13 The fractal dimension increases as the filler volume fraction increases when addition of clay, silica, zinc oxide and aluminum oxide particles in CT 200 epoxy resin, LY/HY5052 epoxy resin.

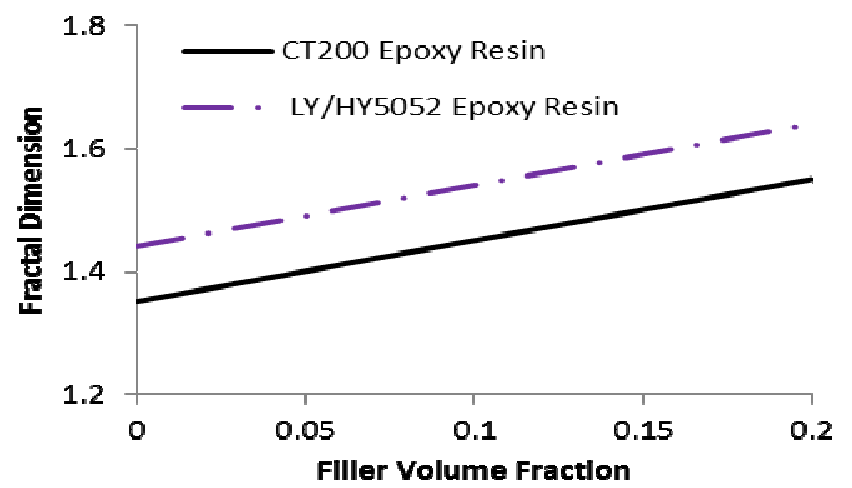

Fig. (13) Effect of filler volume fraction on fractal dimension with the fractal dimension of Epoxy materials 


\section{CONCLUSIONS}

- Adding nano-fillers of Clay, ZnO, and Silica into CT200 Epoxy Resin, LY/HY5052 Epoxy Resin have been induced high improvement in the lifetime of insulation, the tree growth rate of electrical tree propagation, resistance to electrical tree growth and time to breakdown and lead to increase both fractal dimension and total time of electrical tree growth to failure.

- Adding $\mathrm{Al}_{2} \mathrm{O}_{3}$ nanoparticles have a slightly improvement in the life-time of insulation and the tree growth rate of electrical tree propagation.

- Filler volume fraction increases directly the fractal dimension of Epoxy Resin insulation materials

\section{ACKNOWLEDGMENT}

The present work was supported by the Science and Technology Development Fund (STDF), Egypt, Grant No: Project ID 505.

\section{REFERENCES}

[1] L. Dong, G.Q. Gu, and K.W. Yu, "First Principles Approach to Dielectric Response of Graded Spherical Particles", Physics Review B, Vol.67, pp. 77-84, 2003.

[2] K.W. Yu, and G.Q. Gu, "Effective Conductivity of Composites of Graded Spherical Particles", Physics Letters A, Vol.345, pp.448-452, 2005.

[3] Milton, G.W., "The Theory of Composites", Cambridge University Press, 2002.

[4] H.T. Vo, and F.G. Shi "Towards Model-Based Engineering of Optoelectronic Packaging Materials, Dielectric Constant Modeling", Microelectron J, Vol.33, pp.409-415, 2002.

[5] E.B. Wei, S.P. Tang, "Dielectric Response of Graded Cylindrical Composites", Physics Letters A, Vol.328, pp.395-399, 2004.

[6] M.G. Todd, and F.G. Shi, "Validation of a Novel Dielectric Constant Simulation Model and the Determination of its Physical Parameters", Microelectron J, Vol.33, pp.627-632, 2002.

[7] M. D. Noskov, A.S. Malinovski, , M. Sack, and A.J. Schwab, "Self-consistent Modeling of Electrical Tree Propagation and PD Activity", IEEE Transactions on Dielectrics and Electrical Insulation, Vol. 7, No. 6, pp.725-733, 2000.

[8] T. Tanaka, A. Matsunawa, Y. Ohki, M. Kozako, M. Kohtoh, Sh. Okabe, "Treeing Phenomena in Epoxy/Alumina Nanocomposite and Interpretation by a Multi-core Model", IEEJ Trans Fundamentals and Materials, Vol. 126, No. 11, pp. 1128-35, 2006.

[9] H.Z. Ding and B. R. Varlow, "Thermodynamic Model for Electrical Tree Propagation Kinetics in Combined Electrical and Mechanical Stresses", IEEE Transactions on Dielectrics and Electrical Insulation Vol. 12, No. 1, pp. 81-89, 2005.

[10] R. Kurnianto, R. Kurnianto, Y. Murakami, N. Hozumi, M. Nagao, and Y. Murata,;, "Some Fundamentals on Treeing Breakdown in Inorganic-filler/LDPE 
Nanocomposite Material", IEEE, Annual Report Conference on Electrical Insulation and Dielectric Phenomena (CEIDP), pp. 373-376, 2006.

[11] H. Ding and B. R. Varlow " Electrical Treeing Studies on the Araldite Lymy 5052 Epoxy Resin Over A Wide Range of Stressing Voltage", IEEE, Annual Report Conference on Electrical Insulation Phenomena (CEIDP), pp.306-309, 2004.

[12] A.A. Al-Arainy, M.I. Qureshi; and N.H. Malik, "Investigations of Electrical Trees in XLPE Cable Insulation Samples Using PC Based On-Line Monitoring. in Properties and applications of Dielectric Materials", IEEE, 8th International Conference on Properties and Applications of Dielectric Materials,pp. 115-118, 2006.

[13] R. Kurnianto, Y. Murakami, N. Hozumi, and M. Nagao, "Electrical Tree Propagation in Epoxy Resin under Different Characteristics in Electrical Insulating Materials", International Symposium on Electrical Insulation Materials, Vol. 3, pp. $718-721,2005$.

[14] S. S. Bamji, "Electroluminescence-A Technique to Detect the Initiation of Degradation in Polymeric Insulation", IEEE Transaction on Dielectrics Electrical Insulation, Vol. 15, No. 3, pp. 9-14, 1999.

[15] R. Huuva, V. Englund, S.M. Gubanski, and T. Hjertberg, "A Versatile Method to Study Electrical Treeing in Polymeric Materials" IEEE Transactions on Dielectrics and Electrical Insulation, Vol. 16, No. 1, pp. 171-178, 2009.

[16] H. Z. Ding and B. R. Varlow, "Electrical Treeing Studies on the Araldite LY/HY 5052 Epoxy Resin over A Wide Range of Stressing Voltage" IEEE, Annual Report Conference on Electrical Insulation and Dielectric Phenomena (CEIDP), pp. 306-309, 2004.

[17] S. Raetzke, Y. Ohki, T. Imai, T. Tanaka, and J. Kindersberger, "Tree Initiation Characteristics of Epoxy Resin and Epoxy/Clay Nanocomoposite" IEEE Transactions on Dielectrics and Electrical Insulation Vol. 16, No. 5; pp. 14731480, 2009.

[18] D. Pitsa, G. E. Vardakis, and M. G. Danikas "Electrical Tree Growth Simulation in Nanocomposite Polymers: The Role Of Nanoparticles and Homocharges" IEEE International Conference on Solid Dielectrics, Potsdam, Germany, pp. 1-3, July 4-9, 2010.

[19] J. Theiler, "Estimating Fractal Dimension" IEEE, Journal of Optical Society of America, Vol. 7, No. 6/June, 1990.

[20] A. El-Zein, M. Talaat, and M. M. El Bahy, "A Numerical Model of Electrical Tree Growth in Solid Insulation" IEEE Transactions on Dielectrics and Electrical Insulation Vol. 16, No. 6; pp. 1724-1734, 2009.

[21] J.P. Crine, "A Molecular Model for the Electrical Aging of XLPE", IEEE, Annual Report Conference on Electrical Insulation and Dielectric Phenomena (CEIDP), pp. 608-610, 2007. 


\section{نموذج للتشجير الكهربى في المركبات النانومترية لمواد الايبوكسى العازلة}

التتجير الكهربى هو البة ما قبل الانهيار وهو المسئول على تدهور العزل والانهيار عاى الددى الطويل. ففى هذا البحث قد تم تحسين كلا من العمر الزمنى لانتشار التشجير حتى الانهيار وكذللك معدل نمو التتجير الكهربى

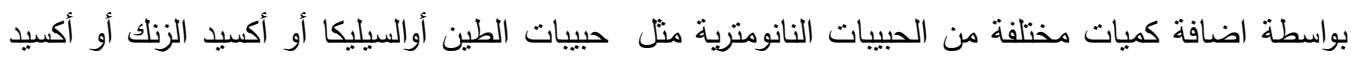

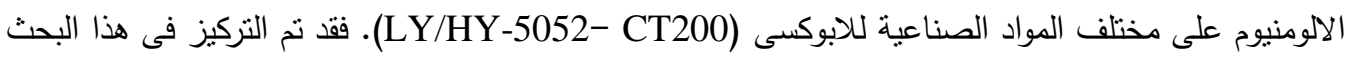

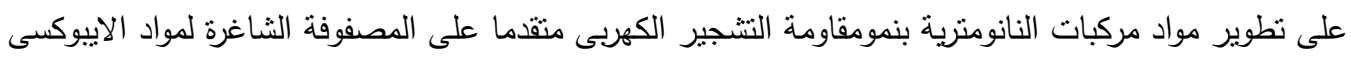

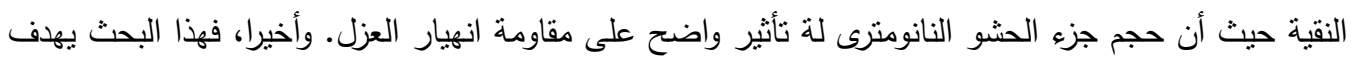

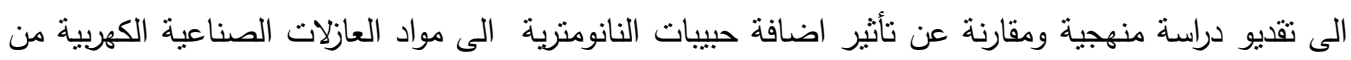

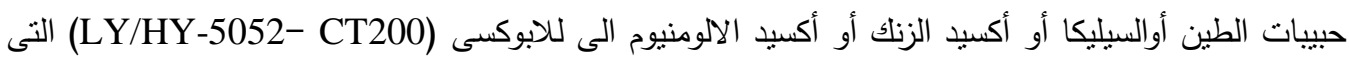

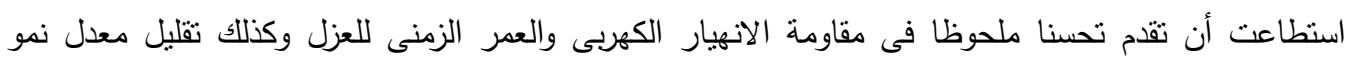

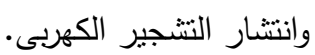

\section{Authors' information}

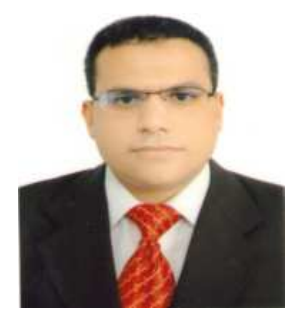

Ahmed Thabet was born in Aswan, Egypt in 1974. He received the BSc (HIE) Electrical Engineering degree in 1997, and MSc (HIE) Electrical Engineering degree in 2002 both from High Institute of Energy, Aswan, Egypt. PhD degree had been received in Electrical Engineering in 2006 from El-Minia University, Minia, Egypt. He joined with Electrical Power Engineering Group of High Institute of Energy in South Valley University as a Demonstrator, Lecture, and as Assistant Professor from 1999 up to date. His research interests lie in the areas of analysis and developing electrical engineering models and applications, investigating novel nano-technology materials via addition nano-scale particles and additives for usage in industrial branch, electromagnetic materials, electroluminescence and the relationship with electrical and thermal ageing of industrial polymers. A lot of mobility's has investigated for supporting his research experience in UK, Finland, Italy, and USA ...etc. On 2009, he had been a Principle Investigator of a funded project from Science and Technology development Fund "STDF" for developing industrial materials of ac and dc applications by nano-technology techniques. He has been established first Nano-Technology Research Centre in the Upper Egypt (http://www.ghson.net/FOLDERS_INDEX/nano/index.htm). He has more than 40 publications which have been published and under published in IEEE journals and conferences and held in Nano-Technology Research Centre website (http://www.ghson.net/FOLDERS INDEX/nano/dr athabet.htm). 